\title{
Article \\ The Individual Nutrition Education Needs among Patients with Type 2 Diabetes at the Public Health Centers in Padang, Indonesia: A Cross-Sectional Study
}

\author{
Ice Yolanda Puri ${ }^{1,2}$, Barakatun-Nisak Mohd Yusof ${ }^{1,3, * \mathbb{D}}$, Zalina Abu Zaid ${ }^{1} \mathbb{D}$, Amin Ismail ${ }^{4}$, Hasnah Haron ${ }^{5}$ (D) \\ and Nur Indrawaty Lipoeto ${ }^{6}$
}

1 Department of Dietetics, Faculty of Medicine and Health Sciences, Universiti Putra Malaysia (UPM), Serdang 43400, Malaysia; iceyolandapuri@ph.unand.ac.id (I.Y.P.); zalina@upm.edu.my (Z.A.Z.)

2 Department of Nutrition, Faculty of Public Health, Andalas University, Padang 25175, Indonesia

3 Institute for Social Sciences Studies, Universiti Putra Malaysia, Serdang 43400, Malaysia

4 Department of Nutrition, Faculty of Medicine and Health Sciences, Universiti Putra Malaysia (UPM), Serdang 43400, Malaysia; aminis@upm.edu.my

5 Nutritional Science Programme, Centre of Healthy Ageing and Wellness, Faculty of Health Sciences, Universiti Kebangsaan Malaysia, Kuala Lumpur 50300, Malaysia; hasnaharon@ukm.edu.my

6 Department of Nutrition Sciences, Faculty of Medicine, Andalas University, Padang 25127, Indonesia; indralipoeto@med.unand.ac.id

* Correspondence: bnisak@upm.edu.my

\section{check for} updates

Citation: Puri, I.Y.; Yusof, B.-N.M.; Zaid, Z.A.; Ismail, A.; Haron, H.; Lipoeto, N.I. The Individual Nutrition Education Needs among Patients with Type 2 Diabetes at the Public Health Centers in Padang,

Indonesia: A Cross-Sectional Study. Nutrients 2022, 14, 1105. https://doi.org/10.3390/nu14051105

Academic Editor: Bahram $\mathrm{H}$ Arjmandi

Received: 21 January 2022 Accepted: 25 February 2022 Published: 5 March 2022

Publisher's Note: MDPI stays neutral with regard to jurisdictional claims in published maps and institutional affiliations.

Copyright: (C) 2022 by the authors. Licensee MDPI, Basel, Switzerland. This article is an open access article distributed under the terms and conditions of the Creative Commons Attribution (CC BY) license (https:// creativecommons.org/licenses/by/ $4.0 /)$.

\begin{abstract}
Background: The Indonesian Public Health Care (PHC) of Management Nutrition Therapy (MNT) guidelines describe that individual nutrition education is aimed to improve quality of MNT services. The guidelines were originally developed for non-communicable diseases (NCDs), not specially for type 2 diabetes mellitus (T2DM) purposes. The reluctance of patients with T2DM to attend individual nutrition education is a common public health care issue in Padang (Indonesia). Methods: The presented cross-sectional study aimed to determine the individual nutrition education needs among people with T2DM. A set questionnaire was distributed to 11 PHC selected from 11 districts in Padang and 179 patients with T2DM were recruited and interviewed. Results: Among the 179 patients with T2DM, 76.5\% were females and housewives (49.2\%), a slight majority (57.8\%) were $\leq 58$ years old and $45.9 \%$ had graduated from primary school. The highest numbers of patients with T2DM were in PHC Andalas (20.7\%). Some 74.9\% (134) of the people with T2DM routinely attended individual nutrition education classes for less than $30 \mathrm{~min}$ (60.3\%). Patients with T2DM followed individual nutrition education at a PHC every 1-2 months (59.8\%), and a majority of the individual nutrition education was given by a medical doctor (57.5\%). In contrast, $42.3 \%$ of patients with T2DM did not attend individual nutrition education due to a lack of recommendation from a medical doctor and their reluctance (33.3\%). Although a majority of patients with T2DM $(62.6 \%)$ were satisfied with their individual nutrition education, $(20.4 \%$ of patients with T2DM recommended the availability of booklets during individual nutrition education that can be read at home. Patients with T2DM needed individual nutrition education (88.8\%) and the majority (25.1\%) requested individual nutrition education topics about diabetes food recommendation. Even though patients with T2DM followed health professionals' advice (78.2\%), however, their HbA1c (76.5\%) wasnot reduced. Patients with T2DM agreed that individual nutrition education can increase their knowledge (51.9\%), unfortunately, they still have difficulty to control their blood glucose (5.6\%). Conclusions: According to the patients with the T2DM perspective stated above, it is crucial to develop the tool kits and educate patients with T2DM following the Diabetes Nutrition Education (DNE) curriculum to improve glycemic control.
\end{abstract}

Keywords: nutritional practices at PHC; patients' with type 2 diabetes perspective; individual nutrition education 


\section{Introduction}

Type 2 diabetes mellitus (T2DM) occurs when the blood glucose level rises excessively because the ineffective body use of insulin. The International Diabetes Federation has estimated that diabetes prevalence has increased by $51 \%$ globally, including about $74 \%$ in South-East Asia [1]. Indonesia is no exception to this trend. The prevalence has increased steadily from 7\% in 2016 to 10.9\% in 2018 [2]. Padang, the capital city in West Sumatera, has not observed the same rises. DM prevalence there increased slowly from $1.3 \%$ in 2013 to $1.8 \%$ in 2018 [2].

Nutrition education, which can be presented in an individual or group setting, is an essential component in T2DM management to learn appropriate nutrition skills. Nutrition education is a method to educate, develop, and maintain the behaviour changes made by patients by enhancing good eating habits [3]. One of the essential components in nutrition education includes meal planning guided by the change behavior model. The purpose is to support the process, set priorities, establish goals, and improve the quality of life [4].

The critical needs of nutrition-related knowledge in facilitating lifestyle changes are well established [5-7]. Consumption of healthy diet is a key to improving T2DM control. Medical nutrition therapy (MNT) guidelines recommend a reduction in energy and saturated fat intake but increased consumption of high fiber foods (fruits and vegetables), whole grains, and legumes [5-7]. Furthermore, patients with T2DM require a set of skills in managing their carbohydrate intake, which can be thought to include carbohydrate counting, exchange systems, food pyramids, healthy plates and meal planning depending on their skills and comprehension. Others proposed topics include explaining diabetes pathophysiology, meal frequency, cooking methods, fiber and whole grains intake and healthy eating [7-10]. In The Netherlands, when patients received quality education with face-toface consultations, they did not benefit much from 3-6 months visits. Patients still embarked on unhealthy lifestyles practices, which suggests the critical need for self-management, especially lifestyle changes [11]. Hence, nutritionists released a community-based food education program that significantly increased nutrition-related knowledge provided via face-to-face. This is because face-to-face education allows individuals with T2DM to ask questions and discuss issues [12].

We previously observed that the nutritionists perceived that patients with T2DM were reluctant to attend nutrition education sessions because the education materials were not interesting [13]. Moreover, nutritionists have also perceived that the patients felt fewer benefits from individual nutrition education $[13,14]$. Therefore, a nutritionist should consider patients' needs when developing nutrition education materials, which is crucial to delivering nutrition information related to diabetes. Nonetheless, knowledge about practices and perception, as well as our patients' needs, is scarce. Therefore, this study aimed to determine the need for nutrition education among individuals with T2DM. The results would inform the decision in producing individual nutrition education for patients with T2DM at PHCs in Padang (Indonesia).

\section{Material and Methods}

\subsection{Study Design}

A cross-sectional survey was conducted among patients with T2DM at selected PHCs. A 30-item questionnaire survey that included multiple-choice and open-ended questions was used to allow subjects to deliver their responses in their own way [15]. The patients with T2DM were interviewed about sociodemographics, the individual nutrition education for T2DM patients at PHC, and the need for individual nutrition education. Selected and trained enumerators and who have a nutrition education background delivered the questionnaires, which took around $20 \mathrm{~min}$. The Faculty of Medicine, Andalas University (No. 423/KEP/FK/2019) and the Ethical Committee of Universiti Putra Malaysia (JKEUPM2019-423) approved the study in 2019. 


\subsection{Respondents, Sampling and Study Location}

Respondents (both male and female) who participated in the survey had a confirmed diagnosis of T2DM for at least 6 months, were aged between 18 and 65 years old, and could read, write and communicate well. Respondents were excluded from the study if they had severe diabetes complications such as stroke and renal failure, were pregnant or breastfeeding.

The formula used to calculate the sample size used the cross-sectional study by Aday and Cornelius et al. [16] and the standard deviation $(\mathrm{HbA1c})$, also following a previous study (Rusdiana et al., [17]), as follows:

$$
n=\frac{Z^{2}\left(1-\frac{\alpha}{2}\right) \sigma^{2}}{d^{2}}
$$

where, $\sigma=$ estimated standard deviation $=1.8$ [17], $\mathrm{d}=$ desired precision $(1), \mathrm{Z}^{2}{ }_{1-\alpha}=0.95=1.96$. A total of 179 patients were recruited based on PHC visits from June to July 2020.

\subsection{Study Site and Sampling Procedure}

The study was conducted at Public Health Clinics (PHCs, known as PUSKESMAS in the Indonesian language), located in Padang (Indonesia). These PHCs were located in 11 districts selected randomly from among the 23 available PHCs. One PHC was selected for each district (Figure 1).

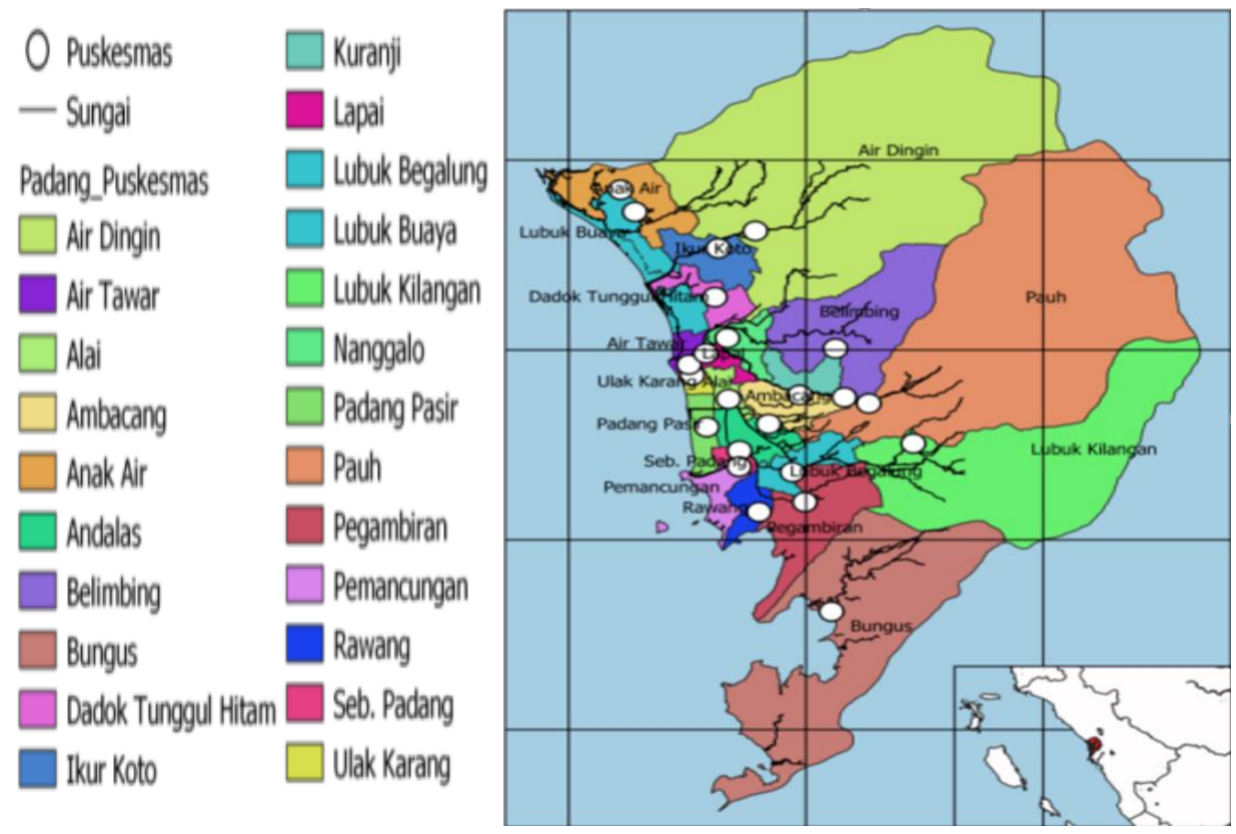

Figure 1. Public health care (PHC) location map of Padang (Google).

Eligible patients based on the criteria were selected using simple random sampling at the 11 selected PHCs. Therefore, the 179 subjects are divided into 11 districts, with 16 or 17 T2DM patients from each PHC.

\subsection{Questionnaires}

The questionnaire consisted of 32 questions in the form of multiple-choice (24 items) and open-ended (six items) questions. The questions were developed based on the Integrated Health Service and Promotion questions for the prevention of non-communicable diseases [15]. The questions were then modified to identify the need for the current nutrition practice among patients with T2DM [11]. This questionnaire consisted of three sections divided into sociodemographics (eight questions), nutrition practices and perception of 
individual nutrition education received at PHCs (14 questions), and the need for individual nutrition education (10 questions).

Enumerators with nutrition education backgrounds were trained to interview the respondents. The interview duration for each patient was less than $20 \mathrm{~min}$. Especially in the case of elderly patients, some of them visited the PHC alone and the rest were accompanied by family members. The questionnaire was pre-tested among 20 patients with T2DM recruited from PHCs in districts outside Padang.

\subsection{Data Analyses}

Descriptive statistics were reported as frequencies and analyzed in SPSS version 25 (SPSS, Chicago, IL, USA). The descriptive statistics were used to describe the respondent's information, including sociodemographic characteristics, current nutrition practices, and the need having individual nutrition education

\section{Results}

A total of 179 respondents participated in the study, of which $76.5 \%$ were females, housewives $(49.2 \%)$, with an average age of 57.5 years old and had attained at least a primary school level education (45.9\%). The highest numbers of respondents were from PHC Andalas (20.7\%, Table 1).

Table 1. Sociodemographic characteristic of patients with T2DM at selected PHCs in Padang $(n=179)$.

\begin{tabular}{|c|c|c|c|}
\hline & Items & $n$ & $\%$ \\
\hline \multicolumn{4}{|c|}{ Sex } \\
\hline- & Males & 42 & 23.5 \\
\hline- & Females & 137 & 76.5 \\
\hline \multicolumn{4}{|c|}{ Age, years } \\
\hline \multicolumn{2}{|c|}{ Mean SD } & \multicolumn{2}{|c|}{$(57.51 \pm 9.61)$} \\
\hline- & $\leq 58$ & 103 & 57.8 \\
\hline- & $>58$ & 76 & 42.5 \\
\hline \multicolumn{4}{|c|}{ Educational level } \\
\hline- & Primary school & 82 & 45.9 \\
\hline- & Secondary school & 74 & 41.3 \\
\hline- & Tertiary school & 23 & 12.8 \\
\hline \multicolumn{4}{|c|}{ Employment } \\
\hline- & Housewife & 88 & 49.2 \\
\hline- & Currently unemployed & 46 & 25.7 \\
\hline- & Currently employed & 45 & 25.1 \\
\hline \multicolumn{4}{|c|}{ Participating Public Health Care (PUSKESMAS) } \\
\hline- & Andalas & 37 & 20.7 \\
\hline- & Nanggalo & 21 & 11.7 \\
\hline- & Air Tawar & 18 & 10.1 \\
\hline- & Lubuk Begalung & 17 & 9.5 \\
\hline- & Belimbing & 17 & 9.5 \\
\hline- & Pauh & 16 & 8.9 \\
\hline- & Rawang & 14 & 7.8 \\
\hline- & Padang Pasir & 12 & 6.7 \\
\hline- & Air Dingin & 11 & 6.1 \\
\hline- & Lubuk Kilangan & 10 & 5.6 \\
\hline- & Bungus & 6 & 3.4 \\
\hline
\end{tabular}

Table 2 shows that $74.9 \%$ of respondents routinely attended an individual nutrition education session for less than $30 \mathrm{~min}(60.3 \%)$ every $1-2$ months $(59.8 \%)$, that was mainly provided by a medical doctor (57.5\%). Most respondents were satisfied with the education 
sessions $(65.4 \%)$ and perceived they had enhanced their overall understanding $(73.2 \%)$ of nutrition. The most common nutrition education materials used by providers were leaflets $(46.9 \%)$ and food models $(24.0 \%)$, with the most common topics being covered foods high in sugars $(28.5 \%)$, the pathophysiology of diabetes $(26.8 \%)$, signs and symptoms $(26.3 \%)$ and sugar consumption recommendations $(22.9 \%)$. Overall, most respondents were satisfied with the current education materials $(62.6 \%)$, but $20.4 \%$ recommended that booklets be provided to read at home.

About $25.1 \%$ of respondents who did not attend the visit routinely expressed that their doctor had not referred them to a nutritionist $(42.3 \%)$ or they not interested in the sessions $(33.3 \%)$. More than $10 \%$ perceived that individual nutrition education sessions would only be needed once upon diagnosis, and a small percentage of the respondents perceived their diabetes was under reasonable control (2.2\%) (Table 2).

Table 2. Nutrition practices and perception about individual nutrition education received at Public Health Center $(n=179)$.

\begin{tabular}{|c|c|c|}
\hline Nutritionists Practices Component & $n$ & $\%$ \\
\hline \multicolumn{3}{|l|}{ Attendance } \\
\hline - $\quad$ Routine visit & 134 & 74.9 \\
\hline - $\quad$ Not routine & 45 & 25.1 \\
\hline \multicolumn{3}{|l|}{ Frequency } \\
\hline - $\quad$ Every 1-2 months & 107 & 59.8 \\
\hline - $\quad$ Every 3-6 months & 7 & 3.9 \\
\hline - $\quad$ Every $>6$ months & 20 & 11.1 \\
\hline \multicolumn{3}{|l|}{ Duration } \\
\hline$-\quad<30 \mathrm{~min}$ & 108 & 60.3 \\
\hline$\geq 30 \mathrm{~min}$ & 26 & 14.5 \\
\hline \multicolumn{3}{|l|}{ Main provider } \\
\hline Medical Doctor & 103 & 57.5 \\
\hline - $\quad$ Nutritionists & 89 & 49.7 \\
\hline - $\quad$ Nurse & 20 & 11.2 \\
\hline \multicolumn{3}{|c|}{ General understanding towards education sessions } \\
\hline - $\quad$ Good & 131 & 73.2 \\
\hline - $\quad$ Moderate & 3 & 1.7 \\
\hline \multicolumn{3}{|l|}{ Satisfaction of education session } \\
\hline Satisfied & 117 & 65.4 \\
\hline - $\quad$ Not satisfied & 18 & 10.1 \\
\hline \multicolumn{3}{|l|}{ Nutrition education materials } \\
\hline Leaflet & 84 & 46.9 \\
\hline - $\quad$ Food Model & 43 & 24.0 \\
\hline - $\quad$ No tool kits & 37 & 21.0 \\
\hline - $\quad$ Poster & 14 & 7.8 \\
\hline - $\quad$ PowerPoint slides & 4 & 2.3 \\
\hline \multicolumn{3}{|l|}{ Satisfaction towards the tool kits } \\
\hline - $\quad$ Satisfied & 112 & 62.6 \\
\hline - $\quad$ Not satisfied & 22 & 12.3 \\
\hline
\end{tabular}


Table 2. Cont.

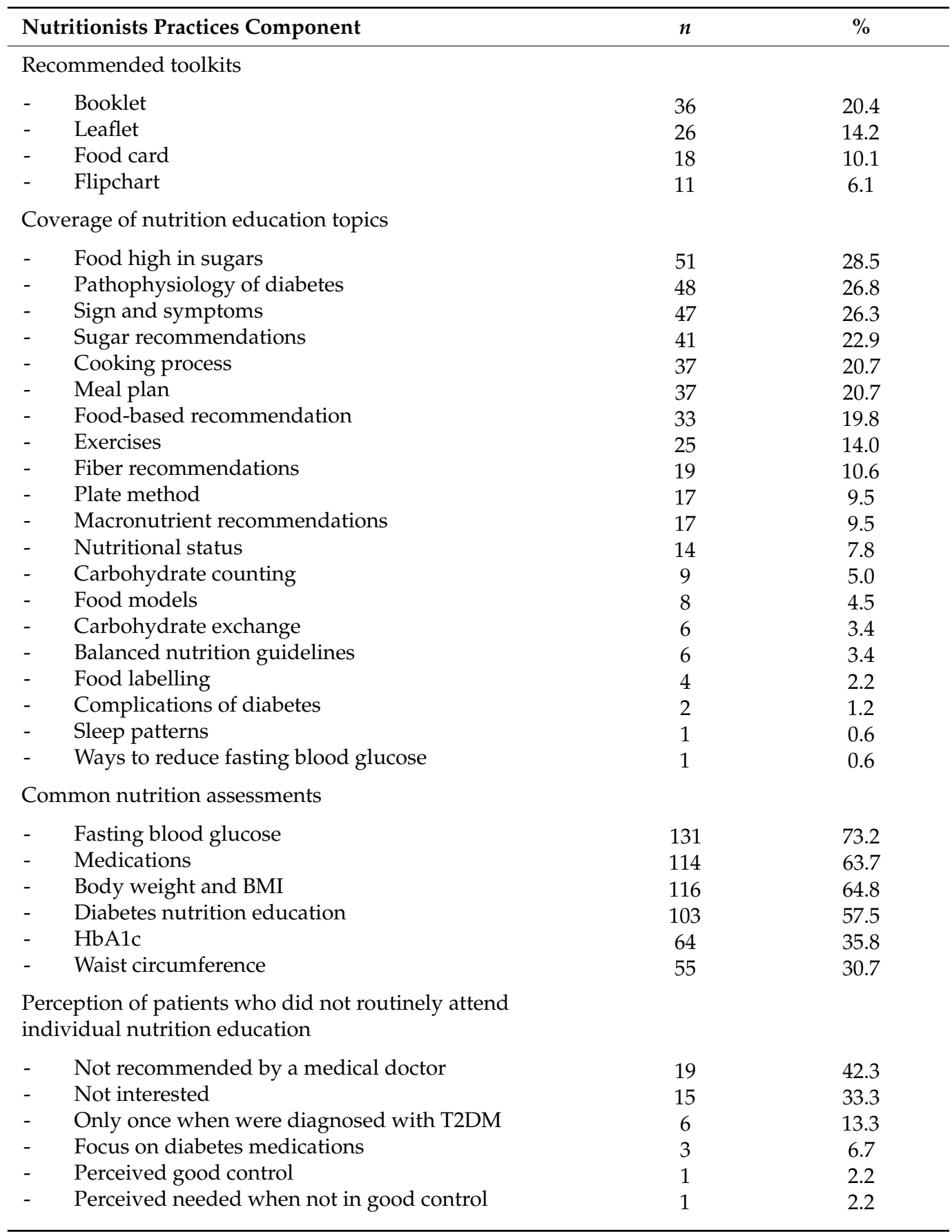

Most of the respondents (88.8\%) expressed a need for nutrition education (Table 3). About $66 \%$ had actively asked questions and the questions were mainly about diabetes foods $(25 \%)$, and other questions such as strategies to reduce blood glucose $(5.6 \%)$ and no improvement was observed even when patients adhered to education $(x \%)$. Although the majority of respondents $(78.2 \%)$ perceived that they followed the education given $(78.2 \%)$, their improvement in blood glucose was minimal (23.5\%). For those who were unable to follow the education given $(17.3 \%)$, their reasons included reluctance to follow the instructions, lack of family support (\%) and special events such as Eid Mubarak (Table 3). Respondents agreed on the benefits of applying the nutrition component, which includes knowledge increase (51.9\%), quality of life increase $(27.9 \%)$, blood glucose decline $(10.0 \%)$, and body weight decrease (1.1\%). 
About $25.1 \%$ of patients with T2DM suggested as individual nutrition education topics several menu plans, $11.2 \%$ symptoms and etiology, and $9.5 \%$ the pathophysiology of diabetes. Therefore, booklets were perceived as appropriate toolkit for reference by patients with T2DM at home.

Table 3. The need for diabetes nutrition education among T2DM patients at PHCs in Padang $(n=179)$.

\begin{tabular}{|c|c|c|}
\hline Items & $n$ & $\%$ \\
\hline \multicolumn{3}{|l|}{ The need for individual nutrition education } \\
\hline - $\quad$ Needed & 159 & 88.8 \\
\hline - $\quad$ No need & 19 & 10.6 \\
\hline \multicolumn{3}{|l|}{ Perception that individual nutrition education is not needed $(n=179)$} \\
\hline - $\quad$ Boring & 12 & 7.2 \\
\hline - $\quad$ Reluctant & 4 & 2.3 \\
\hline - $\quad$ Complicated & 2 & 1.1 \\
\hline \multicolumn{3}{|l|}{ Common questions asked during education sessions } \\
\hline - $\quad$ About diabetes food recommendations & 45 & 25.1 \\
\hline - $\quad$ Strategies to reduce blood glucose & 10 & 5.6 \\
\hline - $\quad$ Reasons for no improvement despite following the advice & 10 & 5.6 \\
\hline - $\quad$ Usage of medication & 9 & 5.0 \\
\hline - $\quad$ Recovery from diabetes & 9 & 5.0 \\
\hline Management of diabetes symptoms & 9 & 5.0 \\
\hline - $\quad$ Portions of foods & 7 & 3.9 \\
\hline - $\quad$ Complications of diabetes & 4 & 2.3 \\
\hline - Weight management & 2 & 1.1 \\
\hline - $\quad$ Sugar recommendations & 2 & 1.1 \\
\hline - $\quad$ Other questions & 12 & 7.2 \\
\hline \multicolumn{3}{|l|}{ Respondents who actively participated during an education session } \\
\hline - $\quad$ Asked questions & 118 & 66.0 \\
\hline - $\quad$ No question & 61 & 34.0 \\
\hline \multicolumn{3}{|l|}{ Able to follow the education } \\
\hline - Yes & 148 & 82.7 \\
\hline - Unable & 31 & 17.3 \\
\hline \multicolumn{3}{|l|}{ Perception of reasons for not following the education } \\
\hline - Reluctance & 20 & 11.1 \\
\hline - $\quad$ Family member influence when they bring food & 4 & 2.3 \\
\hline - $\quad$ Hunger & 2 & 1.1 \\
\hline - $\quad$ Parties for Eid Mubarak & 1 & 0.6 \\
\hline - $\quad$ Nutritionists are rushing because the number of patients is excessive & 1 & 0.6 \\
\hline \multicolumn{3}{|l|}{ Recommended topics } \\
\hline - $\quad$ Menu plans & 45 & 25.1 \\
\hline - $\quad$ Symptoms and etiology & 20 & 11.2 \\
\hline - $\quad$ Pathophysiology of diabetes & 23 & 9.5 \\
\hline - Carbohydrate exchange & 1 & 0.6 \\
\hline High sugar foods & 1 & 0.6 \\
\hline - $\quad$ Balanced Nutrition Guide (Pedoman Gizi Seimbang) & 11 & 6.1 \\
\hline - $\quad$ Plating methods & 2 & 1.1 \\
\hline Provide prescriptions on sugar consumption & 1 & 0.6 \\
\hline - $\quad$ Provide macronutrients & 7 & 3.9 \\
\hline - $\quad$ Carbohydrate counting & 7 & 3.9 \\
\hline
\end{tabular}


Table 3. Cont.

\begin{tabular}{lcc}
\hline Items & $n$ & $\%$ \\
\hline Perceived improvement in glucose control & & \\
- Not improved & 137 & 76.5 \\
$-\quad$ Improved & 42 & 23.5 \\
Perceived benefits of education & & \\
- $\quad$ Knowledge increase & 93 & 51.9 \\
- Quality of life increase & 50 & 27.9 \\
- Blood glucose decline & 18 & 10.0 \\
- Body weight decrease & 2 & 1.1 \\
\hline
\end{tabular}

\section{Discussion}

The study examined the perspectives of patients with T2DM about diabetes nutrition practice adequacy at PHCs in Padang (Indonesia). Patients with T2DM were recruited: (1) when they were diagnosed as new DM patients, (2) had uncontrolled fasting blood glucose, (3) were Prolanis members (T2DM patients who are registered with the Indonesian insurance program). A majority of the T2DM patients were female $(76.5 \%), 45.9 \%$ of them had graduated from primary school and the average age was 57.51 years old. In Indonesia, individual nutrition education should follow management nutrition practices at PHCs established by the Ministry of Health. T2DM patients should receive nutrition counseling besides anthropometry measurements, biomedical and clinical measurements. In Portugal, the primary health care system with community-based intervention provides food education programs and exercise programs as nutrition intervention to improve behavioral change. Nutrition educators used face-to-face education that allowed T2DM patients to ask questions and discuss concerns. Unfortunately, food education programs report lower attendance compared with other educational interventions in T2DM patients [18]. Diabetes care in The Netherlands is currently focused on regular face-to-face consultations for selfmanagement activities such as medical management (DM medicine and dietary advice), behavior and emotional management. Although T2DM patients had adequate $\mathrm{HbA} 1 \mathrm{c}$ ( $\leq 60 \mathrm{mmol} / \mathrm{mol}$ ), however, T2DM patients stated that they perceived no great benefit from the evidence-based guidelines for treatment of T2DM [11].

The study found that T2DM patients stated that there was often no recommendation of a medical doctor $(42.3 \%)$ for education, and they were also reluctant to attend nutrition counseling (33.3\%). Although T2DM patients have good perceptions of nutrition education $(73.2 \%)$, and were mostly satisfied with the educational aid $(62.6 \%)$, T2DM patients suggested providing booklets $(20.4 \%)$ during nutrition counseling. A current study of the perspective of patients with T2DM in Mexico reported that books and infographics were the most common frequently used tools in individual nutrition education and resuted in improved $\mathrm{HbA1c}$ levels [19]. Individual nutrition education improved $\mathrm{HbA1c}$ if patients with T2DM had good diabetes nutrition knowledge and awareness of nutrition education [4]. Individual nutrition education played a role key in diabetes nutrition services and the DM management diet of each individual with T2DM [19]. It is crucial to increase the attendance of patients with T2DM at PHC educational sessions. Several barriers should be considered to avoid bias. These barriers were misunderstanding of the effectiveness of individual nutrition education, confusion regarding when, and how to make referrals, lack of access nutrition services, and the psychosocial and behavioral factors of patients with T2DM [20], including advanced age, and memory loss [19], education level, duration having of DM, and baseline knowledge of DM [6]. Additionally, a cross-sectional study in Saudi Arabia and China mentioned that transportation difficulties, forgetfulness and being busy had an influence on keeping regular medical doctor appointments, regularly attending clinics [20], while lack of interest, and being unable to be contacted, respectively, were mentioned as common barriers in patients with T2DM [21]. Higher attendance of 
individual nutrition education may impact by T2DM prevalence by increasing knowledge levels. As common education methods, face-to-face nutrition education allowed patients with T2DM and nutritionists to ask questions and discuss issues [18]. To improve glycemic control, patients with T2DM should have good DM knowledge and follow a DM diet and nutritionists should prepare and deliver active and effective dietary education classes [22].

A majority of T2DM patients (66.0\%) asked question during nutrition counseling follow the advice of the health professional (82.7\%), and their knowledge increased (51.9\%). Unfortunately, T2DM patients are still reluctant to attend nutrition education classes (11.1\%), and perceived no improvement in $\mathrm{HbA1c}$ levels (76.5\%). A study about MNT from an Indian perspective indicated the importance of developing individual nutrition education topics and providing meal plans with a focus on nutrition intake, healthy food choices, good eating patterns, and food portion size [23]. T2DM patient's perspective in The Netherlands indicated they needed to increase their DM knowledge, to adhere to DM diet management practices, exercise, and regular schedules. Therefore, it is necessary to consider developing tools and strategies, and assess what T2DM patients' need are [11].

In this study, T2DM patients mentioned that the most common nutrition education topics that they received are education about high sugar food (28.5\%), the definition of DM $(26.8 \%)$, and symptoms and etiology $(26.3 \%)$, respectively. The most common question are about DM food recommendations (25.1\%), compared to how to reduce blood glucose $(5.6 \%)$, and why blood glucose does not decrease even after following health professionals' advice (5.6\%). Also, T2DM patients had other question during nutrition counseling such as DM menus, DM meal times, DM exercises and vegetables. Therefore, $25.1 \%$ of T2DM patients requested DM menu plans, and symptoms and etiology of DM $(11.2 \%)$ as nutrition education topics. Since the majority of subjects are elderly from the nutritionists' perspective, patients with T2DM find it difficult to remember the lectures on individual nutrition education topics, therefore, it is crucial to provide appropriate toolkits. According to diabetes health education in Portugal and China, and the perspective of patients with T2DM in Indonesia, booklets are appropriate to deliver individual nutrition education in Indonesia. Patients with T2DM are not familiar with the use of Android for online individual nutrition education. The booklet can address the needs of all patients with T2DM questions during individual nutrition education and practices in their house.

Similar to many of the abovementioned countries, Indonesia also faces challenges in providing individual nutrition education to patients with T2DM. In this study, among those who did not receive education, $42.3 \%$ of them claimed it was not recommended by their doctors, while another $33.3 \%$ were reluctant to attend individual nutrition education classes. Another local study among people with T2DM found that a high level of carbohydrate intake was significantly associated with poor HbA1c. Those who did not adhere to the diet recommendations also had significantly poorer $\mathrm{HbA1c}$ status [18].

Very often, elderly T2DM patients face more difficulties in remembering the lecture content at individual nutrition education classes, therefore, toolkits should be provided to enhance the learning experience. Studies in Portugal, China, and Indonesia have proven that booklets are effective at delivering individual nutrition education to patients with T2DM, especially those who do not have access to or are not familiar with online individual nutrition education. The booklets can be used to address any T2DM questions from the patients that may arise during individual nutrition education and home visits.

\section{Conclusions}

Globally, many countries face challenges in providing effective individual nutrition education to improve the health status of diabetic patients. Indonesia and other countries have similar problems in diabetes individual nutrition education. With the prevalence of T2DM increasing every year, it is crucial to consider a strategy to improve glycemic control in patients with T2DM. Individual nutrition education can offer a diabetes-specific curriculum to educate patients with T2DM and provide knowledge for improving their quality of life. 


\begin{abstract}
Author Contributions: Conceptualization, I.Y.P., B.-N.M.Y., Z.A.Z., A.I., H.H. and N.I.L.; methodology, I.Y.P., B.-N.M.Y., Z.A.Z., A.I., H.H. and N.I.L.; formal analysis, I.Y.P., B.-N.M.Y., Z.A.Z., A.I., H.H. and N.I.L.; investigation, I.Y.P., B.-N.M.Y., Z.A.Z., A.I., H.H. and N.I.L.; writing-original draft preparation, I.Y.P., B.-N.M.Y., Z.A.Z., A.I., H.H. and N.I.L.; writing-review and editing, I.Y.P., B.-N.M.Y., Z.A.Z., A.I., H.H. and N.I.L.; supervision, B.-N.M.Y., Z.A.Z., A.I., H.H. and N.I.L.; funding acquisition, I.Y.P. All authors have read and agreed to the published version of the manuscript.
\end{abstract}

Funding: This research was funded by Andalas University grant, grant number 1676/XIII.R/KPT/2018 and Fundamental Grant Scheme by the Ministry of Higher Education Republic Indonesia (Number: 32253/A2.1/KP/2018).

Institutional Review Board Statement: The study was conducted according to the guidelines of the Declaration of Helsinki, and approved by institutional Ethics Committee for Research Involving Human Subjects at the study site (Faculty of Medicine, Andalas University; No. 423/KEP/FK/2019) and Universiti Putra Malaysia (JKEUPM-2019-423).

Informed Consent Statement: Inform consent was obtained from all of subjects involved in the study.

Data Availability Statement: No supplement data.

Acknowledgments: The authors express tremendous gratitude to all of the study respondents for their contribution. We are also thankful for the all of Public Health Care in Padang, and Department of Health of Padang city.

Conflicts of Interest: The authors declare no conflict of interest.

\title{
References
}

1. International Diabetes Federation (IDF) 9th Edition 2019. Available online: https:/ /www.diabetesatlas.org. (accessed on 20 July 2021).

2. National Health Survey by Indonesian Ministry of Health. Indonesian Basic Data-Riset Kesehatan Dasar (RISKESDAS); Indonesian Ministry of Health: Jakarta, Indonesia, 2013.

3. Shamsudin, J.; Harith, S.; Razak, S.A.; Zainal, N.A. A tailored dietary counselling via diet management tool (DMT) helps dietitian improves short term glycaemic control among type 2 diabetes patients. Int. Arch. Med. 2015, 8, 1-9. [CrossRef]

4. Świątoniowska, N.; Sarzyńska, K.; Szymańska-Chabowska, A.; Jankowska-Polańska, B. The role of education in type 2 diabetes treatment. Diabetes Res. Clin. Pract. 2019, 151, 237-246. [CrossRef] [PubMed]

5. Shan, P.-F.; Li, Q.; Khamaisi, M.; Qiang, G.-F. Type 2 Diabetes Mellitus and Macrovascular Complications. Int. J. Endocrinol. 2017, 2017, 4301461. [CrossRef] [PubMed]

6. Ricci-Cabello, I.; Ruiz-Pérez, I.; Rojas-García, A.; Pastor, G.; Rodríguez-Barranco, M.; Gonçalves, D.C. Characteristics and effectiveness of diabetes self-management educational programs targeted to racial/ethnic minority groups: A systematic review, meta-analysis and meta-regression. BMC Endocr. Disord. 2014, 14, 60. [CrossRef] [PubMed]

7. Evert, A.B.; Boucher, J.L.; Cypress, M.; Dunbar, S.A.; Franz, M.J.; Mayer-Davis, E.J.; Neumiller, J.J.; Nwankwo, R.; Verdi, C.L.; Urbanski, P.; et al. Nutrition therapy recommendations for the management of adults with diabetes. Diabetes Care 2014, 37 (Suppl. S1), S120-S143. [CrossRef] [PubMed]

8. Hendrie, G.A.; Coveney, J.; Cox, D. Exploring nutrition knowledge and the demographic variation in knowledge levels in an Australian community sample. Public Health Nutr. 2008, 11, 1365-1371. [CrossRef] [PubMed]

9. Islam, N.S.; Wyatt, L.C.; Taher, M.; Riley, L.; Tandon, S.D.; Tanner, M.; Mukherji, B.R.; Trinh-Shevrin, C. A Culturally Tailored Community Health Worker Intervention Leads to Improvement in Patient-Centered Outcomes for Immigrant Patients with Type 2 Diabetes. Clin. Diabetes 2018, 36, 100-111. [CrossRef] [PubMed]

10. Muchiri, J.; Gericke, G.; Rheeder, P. Impact of nutrition education on diabetes knowledge and attitudes of adults with type 2 diabetes living in a resource-limited setting in South Africa: A randomised controlled trial. J. Endocrinol. Metab. Diabetes S. Afr. 2016, 21, 26-34. [CrossRef]

11. Van Smoorenburg, A.N.; Hertroijs, D.F.; Dekkers, T.; Elissen, A.M.; Melles, M. Patients' perspective on self-management: Type 2 diabetes in daily life. BMC Health Serv. Res. 2019, 19, 605. [CrossRef] [PubMed]

12. Hemmati Maslakpak, M.; Razmara, S.; Niazkhani, Z. Effects of Face-to-Face and Telephone-Based Family-Oriented Education on Self-Care Behavior and Patient Outcomes in Type 2 Diabetes: A Randomized Controlled Trial. J. Diabetes Res. 2017, $2017,8404328$. [CrossRef] [PubMed]

13. Puri, I.Y.; Mohd Yusof, B.N.; Abu Zaid, Z.; Ismail, A.; Haron, H.; Lipoeto, N.I. Currents Nutritional Practices of Nutritionists in the Management of Type 2 Diabetes Patients at Public Health Centres in Padang, Indonesia. Nutrients 2021, 13, 1975. [CrossRef]

14. Arifin, B.; van Asselt, A.D.I.; Setiawan, D.; Atthobari, J.; Postma, M.J.; Cao, Q. Diabetes distress in Indonesian patients with type 2 diabetes: A comparison between primary and tertiary care. BMC Health Serv. Res. 2019, 19, 773. [CrossRef] [PubMed]

15. Ariane, C.P. Buku Pintar Kade Posbindu, 1st ed.; Kementrian Kesehatan Republik Indonesia, Indonesian Ministry of Health: Jakarta, Indonesia, 2019. 
16. Aday, L.A.; Cornelius, L.J. Designing and Conducting Health Surveys: A Comprehensive Guide; John Wiley \& Sons: Hoboken, NJ, USA, 2006.

17. Rusdiana Savira, M.; Amelia, R. The effect of diabetes self-management education on Hba1c level and fasting blood sugar in type 2 diabetes mellitus patients in primary health care in binjai city of north Sumatera, Indonesia. Open Access Maced. J. Med. Sci. 2018, 6, 715-718. [CrossRef]

18. Vasconcelos, C.; Cabral, M.; Ramos, E. The Impact of a Community-Based Food Education Program on Nutrition-Related Knowledge in Middle-Aged and Older Patients with Type 2 Diabetes: Results of a Pilot Randomized Controlled Trial. Int. J. Environ. Res. Public Health 2019, 16, 2403. [CrossRef] [PubMed]

19. Almeda-valdes, P.; Martagón, A.J.; Galán-ramírez, G.A.; Aguilar-salinas, C.A. Empowerment of patients with type 2 diabetes: Current perspectives. Diabetes Metab. Syndr. Obes. Targets Ther. 2019, 12, 1311.

20. Badedi, M.; Solan, Y.; Darraj, H.; Sabai, A.; Mahfouz, M.; Alamodi, S.; Alsabaani, A. Factors Associated with Long-Term Control of Type 2 Diabetes Mellitus. J. Diabetes Res. 2016, 2016, 2109542. [CrossRef] [PubMed]

21. Zhang, Y. Effectiveness of Systematic Health Education Model for Type 2. Int. J. Endocrinol. 2018, 2018, 6530607. [CrossRef] [PubMed]

22. Sami, W.; Ansari, T.; Butt, N.S.; Rashid, M.; Hamid, A. Effect of diet on type 2 diabetes mellitus: A review. Int. J. Health Sci. 2017, $11,65$.

23. Viswanathan, V.; Krishnan, D.; Kalra, S. Insights on Medical Nutrition Therapy for Type 2 Diabetes Mellitus: An Indian Perspective. Adv. Ther. 2019, 36, 520-547. [CrossRef] [PubMed] 